\title{
GESTO, COISA E NÃO-COISA NA FENOMENOLOGIA HERMENÊUTICA DE V. FLUSSER
}

\section{Helena Lebre}

Centro de Filosofia da Universidade de Lisboa

\section{A Parafenomenologia flusseriana}

"Nada procuremos por trás dos fenómenos. Eles próprios são o ensinamento"

Goethe

Como se sabe, o fundador da fenomenologia, enquanto ciência dos fenómenos metodologicamente estabelecida, foi Husserl. A ele se atribui, desta forma, a responsabilidade de iniciar uma tradição, na medida em que ao traçar um caminho possível de se fazer filosofia (no ensejo de considerá-la como uma "ciência de rigor"), abriu percursos alternativos os quais originaram novos contornos e configurações e esboçaram aberturas para outros contextos propiciadores de visões do Mundo, umas renovadas e outras radicalmente diferentes. Neste sentido constituem elas próprias, novos modelos cujas reflexões são reconhecidamente paradigmáticas. O comum, no entanto, consubstancia-se na tentativa de buscar um olhar outro, um gesto novo que permita encontrar o ainda não encontrado, revelar o ainda velado.

Será este o ponto de partida para os esboços fenomenológicos praticados por Vilém Flusser, exercícios fenomenológicos - hermenêuticos - existenciais, modelo triangularpresentenas suas prolíferas reflexões filosóficas: efectivamente, pretende conciliar "estabelecer pontes", segundo a sua própria expressão, entre a filosofia da linguagem, em especial Wittgenstein, e a hermenêutica existencial, referindo-se, sobretudo, a Heidegger, utilizando como instrumento privilegiado uma metodologia importada da fenomenologia de Husserl. 
Redefinindo o "voltar às coisas mesmas" husserliano, sobretudo, pela significação que o conceito de coisa adquire (Ding - coisa existente e não Sache - res latina - assunto) ${ }^{1}$, Flusser acabará por integrar no método em causa aspectos que, embora não o desvirtuando, são originais e necessários para a investigação que pretende empreender.

Mantém-se, no entanto, uma atitude fenomenológica, à qual se acrescenta uma forte dimensão interpelante, mesmo no que se refere à proficuidade do método em causa, permanecendo o enfoque no descrever (descrição fenomenológica), numa consciência capaz de doar sentido pela sua competência de dirigir-se às coisas (intencionalidade) e na abstração de todos os preconceitos e hábitos que obstam a uma percepção mais profunda do Mundo (epoché). A valorização da fenomenologia enquanto método é muito evidente na aceitação e no reconhecimento da indispensabilidade da suspensão do juízo, herança vinda de Husserl, mas igualmente devedora da filosofia cartesiana e da função que a dúvida nela desempenha, discordando Flusser, no entanto, do carácter transitório e auto-aniquilante que este conceito assume no Filósofo Moderno. ${ }^{2}$

Este enfoque particular na suspensão do juízo remeterá para a análise da fecundidade da ideia de esquecimento, substituto flusseriano da epoché :

\section{(...) se não tiver nada para esquecer (...) não verei nunca nada" ${ }^{{ }^{3}}$}

Permanece a ideia de fenómeno como um aparecer, que será sempre, para o autor, fenómeno linguístico/simbólico; mantém-se, igualmente, a dimensão da intencionalidade, enquanto movimento da consciência como consciência de algo, acrescentando-lhe uma manifestação descritiva, quase pictural, dada pelo exame assente na gestualidade. Será através desta "objectivação da consciência" que se revela em cada gesto, desta "gesticulação da consciência" que se constitui a condição de possibilidade de um incessante interrogar cujo fluxo da realidade impõe e ao qual co-responde o ser humano, pela procura de sentido - a consciência do mundo obriga a doar um sentido ao mundo. O homem fá-lo-á, antes de tudo, pela dádiva do nome, posterior ao gesto, gesto que se

1 A noção de Ding é a noção de produto, e enquanto tal, fabricação cultural e artificial: algo, cuja definição entronca na materialidade, estando à disposição de...

2 A importância da dúvida vai Flusser beber a DESCARTES, 1949, "A la recherche de la vérité" in Oeuvres et lettres, Paris, Gallimard - Bibliothèque de la Pleiade, na identidade lógica e ontológica entre duvidar/pensar/ existir

3 FLUSSER V., 1993, Dinge und Undinge, phänomenologische Skizzen, München, C. Hanser [ed. consultada: trad. fr. J. Mouchard, Choses et non-choses, esquisses phenomenologiques, Nimes, éd. Jacqueline Chambon, 1996, p.70 
faz nome/palavra/linguagem ${ }^{4}$ que, por seu lado, será anterior ao pensamento. Este último funciona ordenando e articulando a palavra, extraindo-se, desde logo, a consequência de que o âmbito epistemológico sucede ao ontológico, cujo enquadramento e dinâmica se reduz à descrição do nome (língua) no seu realizar-se. A afirmação precedente torna-se compreensível considerando a homologia Língua/Realidade: o contexto linguístico-semântico é ontológico e vice-versa.

"O objetivo deste trabalho é contribuir para a tentativa de tornar consciente a estrutura desse cosmo [realidade concreta]. Será proposta a afirmação de que essa estrutura se identifica com a língua. Que conhecimento, realidade e verdade são aspetos da língua. Que ciência e filosofia são pesquisas da língua. E que a religião e a arte são disciplinas criadoras da língua." ${ }^{5}$

Ao longo da sua obra, este processo investigativo alicerçado na fenomenologia manter-se-á assim como o estilo de ensaio que considera ajustado para o discorrer de todas as perplexidades: primeiro uma análise fenomenológica da linguagem (Língua e Realidade); posteriormente, uma interpelação sobre os fenómenos do Mundo, da Natureza e da Cultura (Natural:mente e Ficções Filosóficas); na esteira das anteriores, uma avaliação fenomenológica sobre os hábitos do quotidiano e dos gestos rotineiros numa descrição e interpretação do nosso Lebenswelt (Dinge und Undinge et Les Gestes), numa espécie de fenomenologia do gesto e do olhar.

Pode afirmar-se que a filosofia flusseriana, perspectivada a partir do método, escora-se na análise fenomenológica da linguagem, concluindose a identidade lógica e ontológica da Língua-Realidade, sendo que todo o posterior caminho advém deste primeiro princípio. $\mathrm{Na}$ descrição desta relação de identidade vão-se encontrando consequências e conclusões, novos dados que permitem pôr as questões da Língua, estritamente colocada, em questões que tendem para a comunicação, convertendo, portanto, o âmbito da linguagem sem dela fugir, mas albergando novos conceitos, novas articulações e gesticulações, espelho do Mundo e do Homem. Análise da palavra, análise do gesto, análise da imagem e do olhar: percurso que se vai cumprindo através de uma fenomenologia sui generis, à la Flusser:

4 Curioso que aqui se detecte o cruzamento entre uma filosofia analítica e pós- analítica com a fenomenologia. Michael Dummet, por exemplo, afirma que o que é próprio da filosofia analítica é tratar da linguagem como anterior ao espírito, i e, que o pensamento é essencialmente linguístico.

5 1963, Lingua e Realidade, S. Paulo, Herder, [ed. consultada: Língua e Realidade, S. Paulo, Annablume, 2007, p.33-34] 
"Remover neblinas, e tentar mostrar que são neblinas e não algo, me parece ser a única atitude digna. Optei contra a profundidade a favor da superficialidade. Porque creio que por trás da neblina não se esconde algo profundo, mas que a neblina é uma ilusão que esconde superfície concreta por trás da qual nada se esconde. Isto não é, como parece, jogo de palavras. Ao contrário dos pensadores profundos, não creio que a meta última seja chegar até ao fundo da neblina, mas que, depois de rasgada a neblina, começa a verdadeira tarefa: a de tentar apreender e compreender a superfície exposta. $\mathrm{O}$ pensamento profundo me parece ser mais superficial que o pensamento que procura captar a superfície das coisas." 6

\section{A epoché enquanto esquecimento intencional}

"A verdadeira viagem à descoberta consiste não em visitar novos lugares [...] mas em observá-los de outra forma." Marcel Proust

Se nos interessa saber do mundo em que vivemos, temos de disciplinar o olhar. Abandonar uma certa iliteracia do ver, situação ilegítima que inviabiliza a visibilidade, que o hábito constrói e do qual se alimenta. Atentar que a atitude natural e espontânea, na verdade, não o é, mas está condicionada e armadilhada pelo que se julga saber, por uma não consciência do que está à nossa volta, a qual nos coloca na posição de meros utilizadores de coisas que, por seu turno, se definirão pela sua serventia, obrigando-nos a um estar submetido a, um servir-se de? .

A dificuldade está nesta postura artificial de indiferença porque irreflectida, que nos constrange e, pode impossibilitar o fazer tábua rasa de todos os conhecimentos ou juízos de valores em relação às coisas, origem indispensável para a conquista desse olhar outro.

Suspender o juízo é, então, um processo deliberado de esquecimento. $\mathrm{O}$ propósito de esquecer, sendo uma opção, é obviamente difícil, mas necessário: do seu sucesso depende a fecundidade do método. Efectivamente, conhecer algo é, também, perceber a instrumentalização que fazemos dos objectos, reconhecer que eles servem para alguma coisa, que têm uma finalidade. Nunca poderá ser, no entanto, esta vinculação redutora um sinónimo de conhecimento. Aquela é tão-somente uma dimensão técnico-prática que

${ }^{6}$ FLUSSER. V, 1979, Naturalmente Vários Acessos ao Significado de Natureza, S. Paulo, Livraria Duas Cidades, p. 128.

${ }^{7}$ O problema subjacente, e, que atravessa uma boa parte da obra do autor é o da Liberdade. A partir da década de 70,esta preocupação está presente de uma forma sistemática e explícita. 
qualquer objecto possui, visto a coisa ser um produto/produção/fabricação (o referencial proposto é a coisa cultural). Realmente, as coisas do mundo não são, apenas, a utilidade que têm. E se o acto de conhecimento é um acto intencional e voluntário, então o esquecimento destes aspectos também o será: este esquecer erigido em método, este artifício da memória, dita que se deve esquecer a serventia das coisas, sob pena de tal não ser ultrapassado e constituir-se como uma relação (homem/produto) propiciadora da alienação e auto-alienação do ser humano.

Estamos perante uma das complexidades do esquecer: suspender o que sabe, é apelar para uma crença, para a certeza, que se constitui como improvável, que o olhar face ao mundo possa ser imparcial, neutro e inocente. A verdade é que fazê-lo é impraticável. Vivemos na parcialidade de todas as perspectivas possíveis que determinam o olhar: poder-se-á escolher entre as perspectivas várias? Qual é a mais ajustada à descoberta de novos aspectos ainda não des-cobertos? Irrespondível, mesmo quando se muda de perspectiva e haja a hipótese de esquecer deliberadamente a primeira. ${ }^{8}$

Não há um "puro olhar fenomenológico", o conhecimento prévio, já sedimentado na convenção e devidamente codificado, dá a forma ao olhar. Efectivamente, ao afirmar-se, por exemplo, que algo é triangular, isso pressupõe conhecimentos de geometria, mesmo que não seja a geometria o objecto de estudo (exemplo retirado do autor). $\mathrm{E}$ a isso ninguém se pode furtar, ainda que esse fosse o ideal requerido. Evidencie-se que as coisas aparecem inseridas num todo, não apenas porque fazem parte dele como elementos isolados num conjunto, mas porque se definem pela diferença necessária, indispensável à relação umas com as outras que, de alguma forma, lhes dá ser. Da mesma forma, o gesto percepcionante do sujeito que as capta é resultado desse todo. ${ }^{9}$

Só é possível a epoché até a um limiar determinado: o esquecimento intencional e voluntário acontece ao nível de alguns olhares, de algumas perspectivas e usos recorrentes. O esquecimento integral é uma impossibilidade onto-existencial; seria "uma experiência da vertigem ontológica concreta", para empregar a expressão do autor, sob pena de ausência de qualquer fundamento ou de qualquer certeza, mesmo que referencial, ainda que, em termos teóricos e lógicos, seja concebível. Olhar como quem esquece o que já se olhou é enfrentar a coisa mesma e não reenviá-la para outros cenários

${ }^{8}$ O caso do coelho-pato é paradigmático, quer para as teorias da percepção, quer para esta problemática relativa às perpectivas.

9 Interessante, a relação da dimenșão gestual, a importância desta "consciência que gesticula" e por isso intenciona, com as teorias da percepção nomeadamente o Gestaltismo. Não é por acaso que a raiz latina de gesto/ gestos (gestu e gesta) seja a mesma de gestalt (configuração) e de gestação. 
onde ela, eventualmente, também cabe. $\mathrm{O}$ esquecimento, enquanto acto de vontade, é já princípio de compreensão, e é-o porque decisório: considerar o que é essencial esquecer, leva, necessariamente, a inquirir «qual a essência da visão a ter em conta em relação às próprias coisas»? Mais aprofundadamente: «a apercepção da essência de algo está dependente de quê»?

Dando continuidade aos argumentos propostos, seríamos levados a numa primeira aproximação afirmar que esta dependerá, não daquilo que procuramos, mas do modo como o fazemos: a apercepção da essência de algo está no modo como nos abrimos a uma coisa. Há aqui um deslocar óbvio do problema: da coisa, como o aspecto aparentemente nuclear da relação, passase para o papel central do sujeito. A consciência de algo é, por isso mesmo, também consciência de si, autoconsciência: as descobertas das coisas do Mundo dizem-nos tanto sobre elas como sobre nós próprios. Diz-nos Flusser:

É conhecida a tendência humana para «espelhar-se» nos seus produtos. O processo é aproximadamente este: o homem projeta modelos para modificar a realidade. Tais modelos são tomados do corpo humano. Por exemplo o tear tem por modelo o dedo humano, e o telégrafo o nervo humano. O modelo é realizado na forma de um produto. Em seguida, o modelo humano por trás do produto é esquecido, e o modelo se estabelece, por sua vez, em modelo para o conhecimento e comportamento humano. Por exemplo: as máquinas a vapor são tomadas como modelos do homem no século 18 , as fábricas químicas no século 19 , e os aparelhos cibernéticos atualmente. ${ }^{10}$

A consistência do método fenomenológico, para lá de todas as fraquezas e vacilações, reside na possibilidade desta dupla abordagem: por um lado, a rejeição do hábito, da atitude dita natural em direcção a um novo olhar, pelo processo purificador do esquecimento intencional; por outro, a suspensão do preconceito é conseguida e poderá garantir alguma eficiência, porque é, na verdade, fruto de um gesto intencional, gesto em direcção a um saber que se procura. Esta dupla abordagem, no entanto, acabará por evidenciar o carácter paradoxal que a noção de esquecimento (epoché) acaba por mostrar, quando anexado à noção de intencionalidade e de procura. Neste contexto, o começo de todo o saber instaura-se na absoluta necessidade do esquecimento em relação a algo: esta é a condição de possibilidade de encontrar um outro olhar, um olhar que vá mais além. Nada havendo para esquecer, nada haverá para aprender:

10 FLUSSER, V. 1979, Natural:mente Vários acessos ao significado de Natureza, p. 52 
$[\ldots]$ se não tiver nada para esquecer $[\ldots]$ não verei nunca nada" 11

O que está aqui em causa não é, apenas, o que se procura, e, paralelamente, que se esquece, embora também seja, mas a natureza do próprio esquecimento. O ser do esquecimento, pensado dentro deste processo de descoberta, é revelador: o esquecimento manifesta o outro de si - a memória. Ao encontrarse desta forma, o enfoque já não está mais na relação homem/coisa, mas na relação homem/homem, que também pode ser mediada pelo objecto, embora este último só exista para sujeito porque os outros existem. O que aqui se refere é, claramente, a questão do significado, sendo que se indicia a ideia que o sentido a encontrar no Mundo dá-se na possibilidade das permutas entre o eu e o outro, pela construção de memórias cuja continuidade é possibilitada pelo esquecimento.

As coisas têm um fim, inscrevem-se numa vertente de funcionalidade, para a qual parecem ter sido feitas: como já tinha observado Aristóteles, causa final e causa formal são próximas. As coisas que aqui tratamos são produtos, relevam da sua instrumentalidade, e enquanto tal revelam o criador, o fabricante. Além disso, sendo produtos, são culturais e, nesse sentido, foram produzidas a partir de um gesto criativo e direccionado para o outro - este o seu sentido. A essência do coisa/produto/artificialidade reside fora dela: ela é apenas mediação entre o eu e o outro. É meio de comunicação, canal de comunicação, através de onde o outro se manifesta ("fala"). E se, por um lado, esta fala, pode ser um imperativo, um condicionante, um obrigar a ... (pela serventia, o consumismo), por outro lado, a presença, a consciência da marca dos outros nas coisas, possibilita a reflexão - o outro é espelho do eu - e a libertação do utilitário, percebido como exclusivo, que está preso ao objecto. Em suma,

"o que eu descubro, ao considerar as coisas, é o outro enquanto o seu inventor (...) e produtor; e o facto de o descobrir representa para mim mesmo assim como para os outros a experiência vivida do novo". ${ }^{12}$

Por isso, não existe mais objectividade ou subjectividade puras: apenas, sejam quais forem as circunstâncias, intersubjectividade.

${ }^{11}$ FLUSSER V., 1993 Dinge und Undinge, Trad. Francesa de J. Mouchard, Choses e nonChoses, Esquisses phénoménologuiques, Nîmes, Éditions Jacqueline Chambon, 1996, p.70

${ }^{12}$ FLUSSER V, op.citada p. 76. 


\section{III - O gesto, as coisas e as não-coisas.}

[...] narramos quando vemos, porque ver é complexo como tudo." Bernardo Soares, Livro do Dessassossego

O novo olhar, propiciado pelo esquecimento deliberado, é o correlato de um novo gesto que se terá de reconstruir, de se reconverter: o gesto de procurar/ buscar, paradigma de todos os gestos. $\mathrm{O}$ olhar renovado que se busca equivale a uma nova gesticulação que, por sua vez, envolverá uma nova articulação e a consequente inovação dos códigos culturais.

O gesto é a mediação entre o homem e o mundo: o que os distingue é igualmente o que os pode relacionar. Ele é a forma de exprimir uma intenção, de mostrá-la. Mais profundamente, trata-se de pensar o gesto como a intencionalidade ela mesma: a expressão da componente da consciência no seu relacionar-se com, no estar direccionado para. Assim, o gesto é, parafraseando Flusser:

"Um movimento [que] é vivido como (...) livre, quer dizer como um «gesto» (...) [sendo] os gestos estes movimentos livres por definição (...)"13.

Analisar qualquer gesto é sempre reportar uma intenção que nos dirige à coisa, e, simultaneamente estabelecer as fronteiras, os limites entre a consciência e as coisas, entre o eu e o mundo. Evidentemente, que a partir do que foi referido não se pode inferir que não somos seres do mundo, ou que não sejamos porque não estamos nele. A gesta, a gestualidade permite, no entanto encontrar a diferença da quiddidade das coisas e da condição humana. Somos seres-no-mundo, mas simultaneamente somos seres em confronto com as coisas: a nossa condição define-se pela identidade, mas também pela diferença, pela oposição e pelo enfrentamento.

$\mathrm{O}$ gesto permite essa negatividade: se me relaciono com o mundo, no acto de o fazer, estou a retirar-me, a distanciar-me, a definir os contornos da diferença entre o eu por um lado e o mundo por outro. Reentro nele, pela afirmação dessa diferença e pelo gesto que pratico, empresto sentido ao mundo e ao eu. $\mathrm{O}$ gesto permite a permeabilidade entre termos, autoriza uma espécie de osmose existencial.

A fenomenologia husserliana coloca claramente a diferença entre a consciência que percepciona, consciência intencional e a coisa percepcionada. A primeira nunca é uma coisa, ela própria é uma perspectiva percepcionante

${ }^{13}$ FLUSSER, V.1991, Gesten: Versuch einer Phänomenologie [ed. consultada, trad. fr. M. Partouche Les Gestes, Cergy - Paris, HC-D’ARTS, 1999, p.192 
dos acontecimentos, dos objectos. É por esta dinâmica que a consciência se auto-reflecte e e se autopercepciona como tal.

A filosofia cartesiana precisa das ideias claras e distintas para posicionar o eu e as coisas nos respectivos lugares, i. é, legitimar a sua diferença ontológica.

Flusser fá-lo-á através da noção de gesto, que enforma e informa o eu e o mundo, bem como da noção de perspectiva que clarifica, elucida, o que se apreende dos acontecimentos. É, então, o gesto que permite a fenomenolização, i.é., permite a expressão primeva de uma virtualidade escondida que é actualizada, que nos faz mover entre as coisas que nos rodeiam.

Falamos de coisas como produtos e entre coisas vivemos e conhecemos; não há pensamento sem gesto, o qual devirá palavra. ${ }^{14}$ Efectivamente, a consciência é intencional e o mesmo é afirmar da sua abertura em direcção às coisas: consciência que intenciona, gesto que procura e que ao procurar dá o mundo à consciência.

Ir-se-á mais longe, pela afirmação explícita que toda a existência humana se manifesta por gestos. E a partir da análise dos mesmos, do gesto de falar, de escrever, de destruir, de fazer a barba, de fumar cachimbo, mas também do gesto de fotografar, de fazer vídeos, de telefonar..., assim se descreve toda a vida e se infere das transformações histórica-sociais-civilizacionais que habitamos. O gesto é indubitavelmente, grosso modo, um fenómeno mas é, também, uma interpretação codificada, o que possibilita a realização do pensamento, logo da palavra. Este precisa do gesto para se realizar: apenas se pode admiti-lo, primeiro que tudo, como gesto.

$\mathrm{Na}$ sequência do que foi exposto, parece-me de toda a pertinência conjecturar que, a partir das transformações gestuais que possam ocorrer, da introdução de novos gestos, seja possível perceber a crise de toda uma cultura. E, como sustentáculo do que foi dito, poder-se-á avaliar até que ponto a gesticulação de uma consciência interrogativa, tal como é praticada, é ainda representativa do tempo que vivemos. E reflectir, igualmente, até que ponto o gesto de procurar, que suporta todos os outros, visto que implícita ou explicitamente está sempre presente em qualquer deles, é ainda consentâneo com o que se procura, ou se realmente representa o modo como se deve ou tem sentido fazê-lo. A crítica do autor dirige-se a todo o modelo epistemológicocientífico que se iniciou na Modernidade e que estabeleceu a legitimidade e a finalidade de toda a procura, assente em pressupostos metodológicos, na

${ }^{14}$ Daí a importância dos gestos de escrever (articulação do pensar) e do gesto de falar (dar nome às coisas é devolver as palavras às palavras elas mesmas). 
objectivação progressiva do conhecimento, o qual se poderia pensar como, presumivelmente, neutro.

Tal é manifestamente impossível, não só por alguns anacronismos que se podem atribuir a este buscar "objectivo", mas, igualmente, à sua falência redundante pela inumanidade que ele pressupõe. A exploração das consequências deste exame, que ficará para uma outra ocasião, revela que o gesto de procurar está em vias de transformação. E ela não será, somente, do âmbito metodológico, mas sim ontológico e existencial. Foi todo um projecto historicista que faliu, causado pela crença num conhecimento objectivo, cuja validade, que poderia ser questionada, muito mais o será agora, quando o Mundo em que moramos, que nos é familiar, embora ainda seja de coisas é, igualmente e cada vez mais, de não-coisas. O que são não-coisas? Porque elas são, contrariando toda a lógica Parmenidiana. São os derivados das coisas pelo progresso tecnocientífico. Efectivamente, a expressão "não-coisa" é um contra-senso, sendo que o que se pretende salientar é, exactamente, o seu carácter de absurdidade. Estas últimas são informações que praticamente não necessitam de suporte material ou em que ele é desprezável. Os resíduos de coisidade que nelas podem persistir são irrelevantes.

Inobjetos estão penetrando a circunstância e estão empurrando os objetos rumo ao horizonte. "Informações" é o nome de tais inobjetos (...) As informações atuais que penetram a nossa circunstância para desalojar os objetos são de tipo novo. As imagens eletrónicas nas telas de TV, os dados contidos em computadores, os microfilmes e hologramas e todos estes programas e modelos são a tal ponto "moles" (software) que escapam entre os dedos. São "inconcebíveis" no significado literal do termo. É erro chamá-los "objetos". São inobjetos. ${ }^{15}$

As não-coisas não têm dimensão existencial. São inapreensíveis segundo o modelo epistémico tradicional. Apenas podem ser descodificadas e implicam, por isso, gestos outros, o que corresponde a olhares novos e a toda uma dimensão temporal não linear - a pós-história. Os novos gestos são indício e concretização simultânea do novo mundo (das não-coisas) nascente.

${ }^{15}$ FLUSSER V., 2006 “Do Inobjeto”, ARS, n.8, vol. 4, São Paulo 


\title{
RESUMO
}

A fenomenologia flusseriana propõe-se como um processo, uma estratégia e, simultaneamente, uma crítica: chamar-lhe-íamos uma "fenomenologia interrogativa" ou parafenomenologia cujas indagações são autênticos pontos de "repère", marcas que assinalam limites e estabelecem caminhos, articulando-se em teias referenciais que constroem criativamente um mapa descritor e interpretativo da nossa experiência tal qual é. Como tal, trata-se de uma fenomenologia que se apoia na hermenêutica, sendo que sua a finalidade é de ordem onto-existencial. A análise proposta, a partir do âmago problemático do questionar fenomenológico, é a de virar a atenção para algo sempre manifesto e, muitas vezes, ignorado ou indiferente: uma reflexão sobre o gesto. Esta possível filosofia do gesto permite perceber a relação de uma sociedade/ civilização na qual se anulou o abismo entre o real e o virtual, onde é possível pensar as coisas (Dinge) e as não-coisas/ inobjetos (Undinge), por mais absurda que esta última expressão aparente ser. Mais importante, ainda, é a abertura para a compreensão de uma nova condição humana emergente e o estranhamento de uma sociedade pautada por critério não históricos: a entrada na chamada pós-história.

Palavras-chave: fenomenologia - gesto - coisa - não-coisa.

\begin{abstract}
The "flusserian" phenomenology regards itself as a process, a strategy and, simultaneously as a criticism: it would be named an "interrogative phenomenology" or paraphenomenology whose researches are authentic points of "repère", features that distinguish boundaries and establish paths, connecting them in referential webs that creatively construct a describing and interpretative map of our experience such as it really is. Thus, it is a phenomenology supported by hermeneutics, being its purpose onto-existential. The proposed analysis, from the problematic core of the phenomenological questioning, is that of grabbing the attention to something always expressed and, quite often, ignored or indifferent: a reflection on the gesture. This possible philosophy of the gesture enables the understanding of the relationship of a society/civilization in which the abyss between real and virtual was nullified, where it is possible to think things (Dinge) and the non-things/non-objects (Undinge), as much absurd as this last expression may seem. More important, though, is the openness to the understanding of a new emerging human condition and the strangeness of a society ruled by non-historical criteria: the entrance to the so called post-history.
\end{abstract}

Key-words: phenomenology - gesture - thing - non-thing 